\title{
Learning and Assessment in a Reading Group Format
}

David Harvie

School of Management, University of Leicester

Bruce Philp

Nottingham Business School, Nottingham Trent University

\begin{abstract}
The purpose of this paper is to outline how a traditional learning format - the reading group - was used to deliver a third-year political economy module (Critique of Political Economy). We begin by outlining the module delivery which is student-centred and where assessment is via presentations. The presenter/discussant format we use mirrors that at many academic conferences. Thereafter, we consider the nature of the reading material we used (Marx's Capital (1976)) before discussing the criteria for a good text. Finally, on the basis of these experiences we consider problems and issues that emerged in the reading group format. In concluding we argue that the reading group format has much to commend it, though we would suggest it as a complement to, rather than a substitute for, the more traditional lecture/seminar approach.
\end{abstract}

\section{Introduction}

Political economy modules have played an important role in economics programmes by offering heterodox insights into capitalist economic systems. While heterodox approaches may be considered in sub-disciplinary modules (e.g. industrial economics), the existence of political economy modules gives a profile to non-mainstream theory which is visible. This paper considers a final-year undergraduate political economy module which has been offered on a number of degree programmes at Nottingham Trent University, namely the BA Economics, BA Business Economics and BA Politics programmes. The Critique of Political Economy (CPE) module is organised around a seminal text - namely, the first volume of Marx's Capital (1976) - and is delivered using a student-centred reading group format. We 
use this text because it offers a comprehensive analysis and critique of the capitalist economic system, and it can be presented as the foundation for an alternative system to the mainstream approaches taught elsewhere on these degrees.

The principal aim of this paper is to discuss the way we deliver this module, with the hope that other academics may be able to draw upon and adapt this approach to the advantage of their students. While we would not suggest traditional lectures and seminars be abandoned, we suggest that a reading group format can encourage student-centred, collaborative learning. In addition to advocating reading groups, we also explore here what might be a good work (or works) to be read and discussed. Obviously we have used the first volume of Marx's Capital (1976), but other texts could be used.

The paper is structured as follows. We first consider the CPE module, outlining the reading group format and assessment regime. We then consider the text to be used. In our module we selected the first volume of Marx's Capital (1976). However, other books or collections of readings could be chosen. We go on to consider some of the strengths and problems involved in using reading groups and (more specifically) in using reading groups to introduce students to Marxist thought. Finally, we present our conclusions.

\section{The reading group}

In university research communities and elsewhere 'reading groups' are commonly used to develop our understanding of seminal works. These works might be political or religious in nature, or perhaps concern culture or literature. Reading groups involve: (i) regular meetings held to discuss specific texts; (ii) texts are worked through methodically; (iii) participants agree to read the relevant pages prior to the meeting. While other works may be discussed, the specific text provides the backbone to the discussion and any series of meetings.

Our experience suggests that reading groups are uncommon in social science undergraduate teaching, with more traditional class formats far more frequently adopted by teachers. In the traditional lecture/seminar format academics generally introduce and structure a topic via a lecture, prior to less-structured discussion or student presentation in seminars/tutorials. The emphasis in the traditional model is, in the first instance, on teaching, and it is the lecturer who sets the agenda for student learning. While this approach is useful for classifying knowledge, it is our belief that this can fetter critical thinking and the development of students into independent free-thinkers. If the purpose of education is to encourage students to classify knowledge and to encourage independent, critical thinking, we suggest student-centred approaches (such as in reading groups) have a vital role to play. 
After two introductory lectures the CPE module is entirely student-led via formal presentations. There are two lecturers present in every session, so the module is team-taught. ${ }^{1}$ Each week a group of three or four students gives a 20-minute presentation based on the relevant pages of Capital, plus secondary reading and independent research. The material from Capital ensures structure and continuity to the module as a whole - also it is the material that everyone is expected to read - but beyond this, students have considerable freedom regarding the content and style of their presentation. Following the presentation there is a 10-minute break to allow a second group, who act as discussants, to structure its response. Thus, the format mirrors that of sessions at many academic conferences, except students present and discuss in groups. The discussion is initially confined to the discussants and presenters for a further 20 minutes or so, before being opened up to the whole group. The contribution of presenters and discussants is assessed (and it is here that it is especially useful that two lecturers are present since work is automatically first and second-marked) and, for each student, $45 \%$ of their aggregate module mark is determined by their presentation grades and $15 \%$ by their discussant contributions (two of each).2 Presenters are required to produce a two-page summary of their work to accompany the presentation and this is distributed to the whole class and is provided as evidence to external examiners.

The advantage of this approach, we believe, is that the reading group presentationbased format helps our students to develop confidence, independence and a collaborative ethic. We make clear that we have no interest in monitoring (at least, not for assessment purposes) group dynamics or attempting to judge individual contributions. The responsibility to manage this is placed firmly on the students. In a group of four students, say, it would be perfectly acceptable for just two to present orally, but, the 'silent' pair might respond to questions. Else we would assume their contribution had been concentrated in preparing the handout and doing other background research. ${ }^{3}$ In fact, we stress that the presentation must be a collective effort. Each group member must be familiar with all the material - a simple divvying up a chapter into its constituent sections, say, makes for a poor presentation and a poor mark - and the group must demonstrate that it is collectively aware of the concepts, contradictions and problematics. Moreover, students learn to formulate their own questions (we give topics, based on Capital); this offers an opportunity for less-constrained learning.

Although the structure of our module emerges from a seminal text, we expect students to draw upon secondary material which takes a wide variety of forms. We encourage the students to be critical of Capital and to evaluate its analysis in terms of historical and contemporary relevance. Secondary reading and sources are thus essential elements of the presentation, to be used in conjunction with the 
reading group. In terms of more academic texts, supplementary reading can take the form of historical and contemporary evidence, and alternative Marxian and non-Marxian theories. For example, in the section of the module dealing with Part 8 of Capital (Primitive Accumulation), we suggest Michael Perelman's The Invention of Capitalism (2000), which compares Marx on primitive accumulation with the writings of the classical economists. Additionally we recommend historical work, for example, John Prebble's The Highland Clearances (1963). Contemporary applications are identified - such as Silvia Federici's 'The debt crisis, Africa and the new enclosures' (1990) and Christopher May's (2000) work on intellectual property rights. We also suggest students consider work implicitly or explicitly critical of Marx's account, such as Hardin's seminal 'The tragedy of the commons' (1968). New theoretical interpretations, such as Werner Bonefeld's thesis of the 'permanence of primitive accumulation' (2001), are also explored. Finally, we encourage participants to draw on non-academic material: novels, films, songs, TV shows and so on. All 'great' art is fundamentally about the human condition - the way in which human beings live with themselves and with each other - which is surely also the subject matter of social sciences. ${ }^{4}$ Thus, Abdelrahman Munif's novel Cities of Salt, Roland Joffé's film The Mission and The Clash's song 'Charlie Don't Surf' all deal with primitive accumulation in one way or another. Again, these examples are strictly indicative and reflect our own interests, cultural backgrounds and (perhaps) ages. One former student went through the module with a copy of Capital in one hand and the Bible in the other, which proved an eye-opening experience for us, atheists both.

Underpinning our approach is an intrinsic notion of education: that is, the purpose of education is to 'equip people to make their own free, autonomous choices about the life they will lead' (Bridges, 1992: 92). Three elements can be identified in this liberal tradition: (i) critical and analytical thinking; (ii) comparative thinking; (iii) intellectual open-mindedness. We feel that the reading group encourages each of these facets and we also believe that Capital is an interesting example because through it we are able to explore the nature of the capitalist mode of production and our roles in reproducing (or undermining) it. The normative basis for private property, questions of our individual and socially-necessary labour time, our own place in the labour process with the association between that and the length and intensity of our working day, alienation and fetishism, all have a systematic dimension and subjective relevance for each of us. That is not to say students should subscribe to our (disparate) views - it is their own autonomous views which we wish to develop and foster - but nor will we pretend to be 'objective' when we present various interpretations. Notice one aspect in this is that, except for introducing basic terms at the beginning of the module, it is the students who first present the material, independent of us, to the student group. In addition, the respective 
lecturers have different views (e.g. on the role of markets) and our differences demonstrate 'live' critical dialogue, comparative thinking and intellectual openmindedness. The team-teaching aspect of the module allows us to provide, we hope, a good example of how differences can be articulated and discussed.

An intrinsic notion of education can be contrasted with an instrumentalist approach which, at face value, seems more pragmatic and practical. Radical thinkers suggest this approach involves 'inculcation of specific "facts" in order to effect a specific worldview' (Clarke and Mearman, 2003:60). We would contrast our view, which aims to make students self-aware, helping them develop their understanding of the world around them and their part in it, with alternative views, which serve, functionally or instrumentally, the needs of business. ${ }^{5}$ Of course, there has been a growth in the past ten years in business-orientated economics programmes, BA or BSC Business Economics, for example. Perhaps the demise of radical content in many economics programmes, and the associated reluctance of leading economics departments to appoint non-neoclassical economists/econometricians, is connected to the growth in programmes offering economics for business. The growth of instrumentalism (in this context) may well also be connected to the changing language and structure of education. Most famously, Paolo Freire (1972) has criticised 'banking education', in which students become 'receptacles to be filled by the teacher': the acquisition of knowledge and development of critical faculties are thus broken up into discrete steps as 'learning outcomes', codified across 'levels' of a degree programme.

The model of learning adopted in 'banking education' is an incremental one. Take the analogy with learning to swim. Teachers lead students into the shallow end, with armbands. Thereafter students dispense with the armbands before moving on to swim in the deeper end of the pool, whereupon they might learn different strokes, diving, etc. In this model new concepts are only introduced once earlier ones have been mastered. While this may be appropriate for learning to swim, we do not feel this is always suitable in studying classic texts in political economy. Indeed, the reluctance of some academics to use primary texts may, for some students, do more harm than good, in that such students will not develop the confidence or initiative to go to this material when they could get something from it. In our reading group, based on Capital, we thus confront the student with many difficult concepts and ask only that they attempt to engage with these, understand perhaps only a small fraction of them and get something from the book. After all, this is how most of us approach many texts. 


\section{Choosing the text}

Having discussed the module format and the approach to education underpinning it, let us now turn our attention to the choice of text or texts to be used. In our CPE module we sought to explore the work of one of the most important critical thinkers in human history - Karl Marx. Marx is a controversial choice. One could, in economics (or political economy), select the work of Adam Smith (1970), Friedrich Hayek (1944) or John Maynard Keynes (1973). Clearly Marx's thought is perceived as radical (and misplaced) by many mainstream economists. But even more sympathetic figures - one example is Brewer (1994) - have suggested that Marx's place on economic syllabi is questionable. Others (e.g. Clarke and Mearman, 2003) have proposed that we study Marx because it helps develop critical faculties, which are in some sense functional for capital.

In our reading group format we selected Capital because it interests us most and because its controversial nature is excellent for stimulating discussion.

Methodologically it provides a stark contrast to the individualism and asociality of general equilibrium theory or new classical macroeconomics. Both of us are active researchers working in this area, so in some sense our module is a good exemplar of teaching being informed by research. 6 But, we would go further than this. For us, we do not believe that teaching and research should be considered distinct activities. And, in fact, our experience of 'teaching' the module has provided us with many insights into the nature of social life and the 'meaning' of Capital.

The module came about after the team initially started discussing offering a new third-year module in the area of political economy. It was decided, with the support of our colleagues, to offer a specific module on Marxist political economy. Having decided the content, we also felt that we would like to deliver the module in an innovative way in which educational hierarchies were limited and in which free, creative thinking and collaborative effort were emphasised. 7 The student-led delivery of the module partially diminished the traditional lecturer/student hierarchy, but we could not entirely avoid this since the module team were required to grade students.

After we decided to offer a module in Marxist political economy, we very quickly moved on discuss how we should structure this and what the content should be. Since we come from very different Marxist traditions, and there are diverse schools of thought within Marxism, we very quickly came to the view that Marx's work would serve best to structure the module and that Capital was the best text to use with final-year undergraduates. This led us to ponder using a reading group since both of us have been involved in reading groups outside of university life. Since we focus on Capital's first volume our syllabus is structured into six sections which 
follow the book's own structure: (i) Marx's introduction; (ii) primitive accumulation (Part 8); (iii) commodities, value and money (Parts 1 and 2); (iv) absolute surplusvalue (Part 3); (v) relative surplus-value (Part 4); (vi) wages (Part 6). In the introductory sessions we provide a brief overview of Marx's life and times, introduce students to historical materialism and some of Marx's key ratios - rate of exploitation and so on - and suggest alternative approaches to reading Capital. Following this we systematically study Capital or roughly three-quarters of it.

Our CPE module is constructed around a thorough study of the first volume of Capital. But, why study this particular text? In truth this question embraces a number of questions which can be asked when adopting a reading group module format. First, why read Capital and not, say, Smith's The Wealth of Nations? Second, why read Capital and not a derivative text such as Fine and Saad-Filho's Marx's Capital (2003) or John Roemer's Free to Lose (1988)? Third, why prioritise a single text, as opposed to constructing a syllabus around an extensive and diverse range of sources? ${ }^{8}$

Of course the reason we study Capital is because we are sympathetic to many of the arguments contained in it, and our initial aim was to offer a final year module in Marxist political economy. But there is absolutely no reason one should not structure a module around Keynes, Smith or Hayek. If we were post-Keynesians, for example, it would be fascinating to spend a year studying The General Theory with an interested colleague and a group of students. Indeed, having spent four years reading Capital collectively the prospect of a change is quite appealing: one of us would find The Wealth of Nations fascinating; the other would prefer Hardt and Negri's Empire (2000). 9 The General Theory, The Wealth of Nations and Empire all have similar qualities to Marx's Capital, which make them suitable reading group material. Specifically we feel the following criteria should be considered in selecting a text for a reading group module:

1. Does the text offer an interesting theoretical system which can be compared to theoretical systems taught elsewhere on the degree programme?

2. Is the text controversial and provocative enough to sustain student-led discussion for a full- or half-year module?

3. Is the text still relevant? Can the arguments still be applied to many aspects of our contemporary world?

We believe that The General Theory, The Wealth of Nations and Empire are each marvellously rich and so they satisfy these criteria, as might other texts. Capital, of course, also interests us for research and political purposes, and we feel students enjoy engaging with that aspect of our jobs and lives. We have no difficulty 
appearing interested in this material because we are, and have demonstrated our commitment to it through our research and political activities. In fact, we might argue that as soon as teachers are required to teach material they are not interested in then their labour immediately becomes, in at least one sense, estranged (Harvie, 2006, 2007). It is thus important that the module team, too, are passionate about the text selected. In addition, for a module to be viable, it is essential the students are sufficiently enthused about the text to take the module in the first place.

One can link the issue of student enthusiasm to a trend in universities to view students as sovereign customers. But, interestingly enough, sufficient students each year display tastes at odds with the instrumentalist view of education, as evidenced by a revival in interest in Marxian modules. Saad-Filho concurs with this view: 'Student demand for courses dealing with Marx's work is often overwhelming, leading to oversubscribed classes and lively debates' (2002: 1). While the market impetus of student loans, tuition and top-up fees may reinforce the instrumentalist approach to education, students do demonstrate a thirst for heterodox approaches and interesting, rather than vocational, modules.

Finally, we have thus far identified a single text as the basis for this module. One of us as an undergraduate was taught political economy at first and third year using original sources, but the module was constructed from diverse sources. This has the advantage of identifying controversies and alternatives for students, but it does not give them a thorough introduction to any particular approach, in the same way that a standard microeconomics module gives a thorough grounding in neoclassical microeconomic theory. By focusing on Marx's work the students are offered an alternative system and are not confused by the myriad of heterodox approaches which non-mainstream economics offers. ${ }^{10}$

\section{Reflections}

As is clear from the format of the module, we emphasise learning over teaching. However, there are problems which remain with the module. One of these is that opinions may be offered which do not reflect the beliefs that those students hold; students may instead offer an opinion closest to what they believe the lecturer's opinion to be. We can break this down partly, for example, by making clear our own disagreements so no 'right answer' seems obvious. Team-teaching (or facilitating), in which two colleagues openly disagree about theoretical positions, interpretations and evidence can offer students profound insights into the nature of academic debate and controversy. In addition, we encourage students, as sensitively as we can, to bring their own cultural, religious and political specificities to the discussion. 
Thus we have had Christian and Muslim students bringing their own religiousethical perspective to the mix in the context of discussion over profit, interest, rent and usury. Economic liberals, especially when strong personalities, also liven up debates. Because the module is offered across a range of honours degrees Politics, Economics, Business Economics - multi-disciplinary issues also emerge. ${ }^{11}$

In previous years we did award marks (10\% of the total) for contribution (when not presenter or discussant) with the intention of encouraging participation. This seemed very subjective and was difficult to manage so we abandoned it after one year. In addition we felt that the continual nature of this element of assessment seemed at odds with some of the values of our module. Such assessment/incentive regimes bear comparison with Fordist production methods and the parts in Capital dealing with the pace, regularly and intensity of work. Despite this change, six to eight students are graded on their contributions in each session, as either presenters or discussants. This presents an inescapable contradiction: on the one hand, we are trying to encourage unimpeded discussion; on the other, students are regularly under scrutiny. ${ }^{12}$

To reduce some of this pressure, students are now only required to contribute on the four occasions when they act as presenter or discussant. And, in spite of abandoning this component of assessment, there has been no drop-off in attendance or contribution in class discussion from the rest of the students. ${ }^{13}$ Nevertheless, we do have to grade students as presenters and discussants on two occasions each, and via a phase test (half-way through) and an essay (at the end of the year-long module). Thus, in one sense our role is one of imposing on students a regime which may be functional to the world of work. ${ }^{14}$ However, our own understanding is far more negative: we encourage students to think critically about 'the world of work' (including the 'work' we give them). Indeed we encourage students to challenge the very notion of work and the nature of their university education. This raises the question: how can we offer a module in a university which challenges the nature of work and hierarchies, without imposing work and hierarchies on students? Of course, while we might be able to tinker with this, fundamentally we are faced with inescapable constraints.

Student numbers in our module also do create a problem. Modules must be economically viable or cost-effective. What this means, in practice, is that staff-student ratios cannot be too high. Clearly this requirement is an obstacle to any module structured around discussion (as opposed to lectures), especially if it is team-taught. That is, the time of lecturers must be accounted for. We have enrolled 25-45 students on the module each year. Clearly, at the top end of this range we are presented with potential problems. Some students are unlikely to contribute (when 
not presenting or acting as discussant) because they are too embarrassed to speak in front of such numbers. This problem diminishes through time for many such students, though, as they build confidence presenting and acting as discussants.

Our experience suggests that students can be classified into three types: those who nearly always read the material and engage (approximately 50\%); a second group of students who occasionally contribute (approximately $25 \%$ ); finally, those who almost never contribute, except when acting as presenter or discussant (approximately 25\%). In years when the student group is smaller we do get higher participation rates in classroom discussion and we have found a circle to be the most effective way to encourage participation. When the group gets large we may have a self-selected 'inner' and 'outer' circle, but we believe this can give rise to some disengagement.

A final observation about engagement concerns our responsibilities. We send clear signals, for example by ensuring we learn everyone's name and using it from the beginning of the module (this requires some revision at the start, using the photo sheet downloadable from our virtual learning portal). The room set-up helps; no student does (or can) sit right at the back of the class. But, we do not see ourselves as having sole responsibility to make the module work - indeed this is where we find the suggestion that students are customers to be somewhat problematic. This connotes to us a situation where students can passively consume our product. In place of this we see our relationship with the students in terms of roles and responsibilities; the group, collectively, has a responsibility to make this module what it is. We, as 'teachers', or rather as leaders or facilitators of the module, can attempt to create appropriate preconditions for learning. But, the module is collective in nature. Responsibility for producing an environment conducive to productive discussion is shared between us and the students. 15

\section{Conclusions}

This paper has argued that a reading group format is a useful way for students both to learn about a seminal text and to study the world through the lens of this text. The format is conducive to self-development in that students learn through collaborative interaction with their peers. We know that well-intentioned academics, in economics departments and elsewhere, are consistently looking for alternative ways to foster learning and we recommend this as one. Of course, contradictions emerge. Our module is taught in an environment where aspects of the world of work are reproduced. Any module which seriously and immanently challenges the very notions on which the assessment regime is founded is exposed as contradictory. Further, we should note that both of us use a plurality of teaching and learning 
methods in other modules. Indeed, we are not proposing this as another model to supplant lecture and tutorials, more as another method to allow our disparate students to flourish and develop. In this respect we feel it is an approach which has worked well, for a number of years, alongside other economics modules.

\section{References}

Bonefeld, W. (2001) 'The permanence of primitive accumulation: commodity fetishism and social constitution', The Commoner, 2 (September). At http://www.commoner.org.uk/ Brewer, A. (1995) 'A minor Post-Ricardian? Marx as an Economist', History of Political Economy, 27, 111-146.

Bridges, D. (1992) 'Enterprise and Liberal Education', Journal of Philosophy of Education, 26(1), 91-98.

Clarke, P. and Mearman, A. (2003) 'Why Marxist economics should be taught but probably won't be!' Capital and Class, 79, 55-77.

Deleuze, G. (1995) 'Post script on the Societies of Control', in G. Deleuze, Negotiations: 1972-1990, 177-182, New York: Colombia University Press.

Federici, S. (1990) 'The Debt Crisis, Africa and the New Enclosures', in Midnight Notes (eds), New Enclosures, 10-17, Jamaica Plain, MA: Midnight Notes. Also at http://www.commoner.org.uk/

Fine, B. and Saad-Filho, A. (2003) Marx's Capital, London: Pluto.

Freire, P. (1972) Pedagogy of the Oppressed, Penguin: Harmondsworth.

Hardin, G. (1968) 'The Tragedy of the Commons', Science, 162, 1243-48. At

http://www.sciencemag.org/cgi/content/full/162/3859/1243 and

http://dieoff.com/page95.htm

Hardt, M. and Negri, A. (2000) Empire, London: Harvard University Press.

Harvie, D. (2000) 'Testing Goodwin: Growth Cycles in Ten OECD Countries', Cambridge Journal of Economics, 24(3), 349-376.

Harvie, D. (2006) 'Value production and struggle in the classroom', Capital and Class, 88, $1-32$.

Harvie, D. (2007) 'Academic labour: producing value and producing struggle', in T. Green and G. Rikowski (eds), Marxism and Education: Renewing Dialogues, Vol.1:Opening the Dialogue, London: Palgrave Macmillan.

Hayek, F. (1944) The Road to Serfdom, London: Routledge and Kegan Paul.

Holloway, J. (2001) 'Why read Capital?', Capital and Class, 75 (Autumn), 65-69.

James, C.L.R. (1992a) 'Letters to Literary Critics', in The C.L.R. James Reader, edited by A. Grimshaw, London: Blackwell, 220-242.

James, C.L.R. (1992b) ‘Popular Art and the Cultural Tradition', in The C.L.R. James Reader, edited by A. Grimshaw, London: Blackwell, 247-254.

Keynes, J. M. (1973 [1936]) The General Theory of Employment, Interest and Money. London: Macmillan.

Marx, K. (1976 [1867]) Capital: Volume I. Harmondsworth: Penguin.

May, C. (2000) A global political economy of intellectual property rights: the new enclosures?, London: Routledge/RIPE Studies in Global Political Economy. 
Perelman, M. (2000) The Invention of Capitalism: Classical Political Economy and the Secret History of Primitive Accumulation, London: Duke University Press.

Philp, B. (2005) Reduction, Rationality and Game Theory in Marxian Economics, London: Routledge.

Prebble, J. (1963) The Highland Clearances, Harmondsworth: Penguin.

Roemer, J. (1988) Free to Lose: An introduction to Marxist economic philosophy, London: Radius.

Saad-Filho, A. (2002) The Value of Marx. Routledge: London.

Smith, A. (1970 [1776]) The Wealth of Nations: Books I-III, Harmondsworth: Penguin

\section{Notes}

1 Insofar is as the module is 'taught' at all. The module is student-led and hence the description of us as 'teachers' is ambiguous.'Joint-facilitators' might be a more accurate description of our roles.

2 We have experimented with various weightings. In one year, for example, presentation plus discussant performances counted for just $30 \%$, with a further $10 \%$ available for other classroom contributions. We have also experimenting with the relative weighting of presenter vis-à-vis discussant performances.

3 If group members approach us to make a specific complaint about one of their number not pulling their weight then we are forced to take more of an interest. We would, for example, send an email to a student asking them to make contact with the rest of their group if they had not attended for a couple of weeks in the run-up to their presentation. Students, too, present twice and act as discussants twice. They have an opportunity to take account of past behaviour of other students in selecting their groups for later presentations.

4 Writing from the US in the 1950s, C.L.R. James argued very eloquently that the films of Charlie Chaplin or D.W. Griffith, say, and even radio soap operas were the contemporary equivalents of Shakespeare, reflecting numerous characteristics and contradictions of society (e.g. James, 1992a; James, 1992b).

5 A third position mirrors the 'business-instrumentalism' approach. Many years ago, at another university, one of us acted as teaching assistant to a Marxist colleague teaching a module on Capital. Motivated by his desire to counter the capitalist 'ideologies' being instilled in students in other parts of the curriculum, this Marxist felt compelled to drive these unfortunate students even harder to ensure they would acquire the 'correct', more 'critical' Weltanschauung, even the lazy ones! One is reminded of the oxymoronic concept of socialist accumulation. The point is that just as it is not possible to produce 'good' workers, neither is it possible to produce revolutionaries.

6 In our research we have both explored the overlap between mainstream and Marxian approaches to economics. For example Harvie (2000) has used econometrics to explore Goodwin cycles, and Philp (2005) investigates game-theoretic Marxian economics. However, we are both firmly of the belief that the best place to start, in terms of introducing Marxist thinking to students, is with Capital. We should also note that at level 2 a broader Political Economy module is offered as an option.

7 The aim was thus to have the module delivery reflect some of our values. We do not feel any need to apologise for this since the values underpinning many modules on undergraduate programmes have a strong ideological content.'Banking' education, for example, reflects this. 
8 We could, perhaps, ask a fourth question: why read Capital and not, say, Grundrisse or The Poverty of Philosophy? We choose the first volume of Capital as opposed to other works by Marx because of its content and because it is one of Marx's later works, completed and edited by him.

9 The suggestion of Empire immediately raises the question of which texts we should describe as 'derivative'.

10 A mainstream module may offer a collection of seminal articles for discussion. But, the formal nature of much of this work, together with its 'positive' veneer, makes us doubt such material would be conducive for discussion among undergraduates.

11 This raises political issues. We try to convince the students that we would like to hear their views irrespective of whether they concur with our own.

12 '[J]ust as businesses are replacing factories, school is being replaced by continuing education and exams by continuous assessment. It's the surest way of turning education into a business.' (Deleuze, 1995: 179).

13 Attendance in 2005/06 ran at 88\% for a class scheduled 7.00-9.00pm on a Monday.

14 Of course we are not shy about discussing this role with students in this module and in others we teach. This problem has been discussed by Holloway (2001) who suggests Capital can help us explore these contradictions.

15 We should note that, while the odd session is a little flat, the discussion is often far better and more incisive than in other modules where students are invited to contribute.

\section{Acknowledgements}

The authors would like to thank two anonymous referees for comments on an earlier draft of this paper. We would also like to thank Oli Harrison for constructive feedback on the teaching methods described here. All remaining errors are our own.

\section{Contact details}

David Harvie

School of Management

University of Leicester

University Road

Leicester LE1 7RH

UK

email:d.harvie@le.ac.uk

Bruce Philp

Nottingham Business School

Nottingham Trent University

Burton Street

Nottingham NG1 4BU

UK

email: bruce.philp@ntu.ac.uk 